Brazilian Journal

of Chemical

Engineering

\title{
ISOLATION AND IDENTIFICATION OF YEAST STRAINS FROM SUGARCANE MOLASSES, DATES AND FIGS FOR ETHANOL PRODUCTION UNDER CONDITIONS SIMULATING ALGAL HYDROLYSATE
}

\author{
Madina Kechkar ${ }^{1,2}$, Walaa Sayed ${ }^{3}$, Audrey $\mathrm{Cabrol}^{3}$, Majda Aziza ${ }^{1}$, \\ T. Ahmed Zaid ${ }^{4}$, Abdeltif Amrane ${ }^{3}$ and Hayet Djelal ${ }^{5^{*}}$
}

${ }^{1}$ Centre de Développement des Energies Renouvelables, Algiers, Algeria. ORCID: 0000-0002-1503-8824; ORCID: 0000-0003-2471-9848

${ }^{2}$ Ecole Nationale Polytechnique, Laboratoire de Biotechnologies Environnementales et de Génie des Procédés, Algiers, Algeria.

${ }^{3}$ Univ Rennes, Ecole Nationale Superieure de Chimie de Rennes, Rennes, France. ORCID: 0000-0002-7053-3385; ORCID: 0000-0001-7831-7479; ORCID: 0000-0003-2622-2384

${ }^{4}$ Ecole Nationale Polytechnique, Dépt de Génie Chimique, Laboratoire de Valorisation des Energies Fossiles, Algiers, Algeria. ORCID: 0000-0003-4499-2526

${ }^{5}$ UniLaSalle-Ecole des Métiers de l'Environnement, Campus de Ker Lann, Rennes, France. E-mail: hayet.djelal@unilasalle.fr, ORCID: 0000-0002-5619-2633

(Submitted: March 26, 2018 ; Revised: June 26, 2018 ; Accepted: August 26, 2018)

\begin{abstract}
Yeast strains were isolated from sugar cane molasses (S1), dates (S2) and figs (S3) and the ethanol production was evaluated in batch condition. A comparison was made with the yeast Saccharomyces cerevisiae. The strains showed tolerant characteristics to stressful conditions like salinity and ethanol. The isolated strains produced ethanol; at $20 \mathrm{~h}$ of fermentation ethanol yields were $0.38-0.39 \mathrm{~g}^{-\mathrm{g}^{-1}}$, and the productivities were almost 0.58 g.L $\mathrm{L}^{-1}$. S. cerevisiae and S1 tolerated up to $14 \%(\mathrm{v} / \mathrm{v})$ of ethanol; while interestingly the isolates S2 and S3 were highly tolerant, up to $20 \%(\mathrm{v} / \mathrm{v})$ ethanol. Thus, S2 and S3 could serve as potential strains for

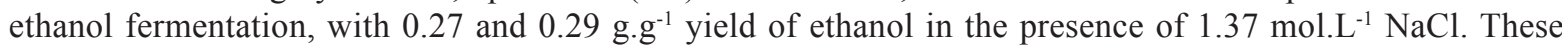
values were higher than the value obtained using the yeast of reference and S1 $\left(0.16 \mathrm{~g} \cdot \mathrm{g}^{-1}\right)$. Co-cultures of S2 and S3 enhanced the ethanol production, increasing the yield of ethanol by $12.5 \%$ compared with the single culture. The strains were identified as species S.cerevisiae, and S2 and S3 were very similar. For an application in the valorization of biomass such as green macro-algae, some assays were done on a synthetic model medium of hydrolysate of macro-algae and the strains S2 and S3 demonstrated excellent fermentative performances. Keywords: Strain isolation; Identification; Saccharomyces cerevisiae; Third generation bioethanol; Batch fermentation.
\end{abstract}

\section{INTRODUCTION}

In view of the potential exhaustion of fossil fuels, geopolitical instability, and deleterious global effects of fossil fuel energy, renewable fuels have gained in popularity due to their sustainability (Sharma et al.,
2008). Obtaining liquid fuels from non-fossil sources is increasing in interest in recent years worldwide, due to their environmental benefits and the fact that they are derived from renewable sources (Demirbas, 2009).

To satisfy the energy needs of modern society in developing economies worldwide, renewable energy

\footnotetext{
*Corresponding author: Hayet Djelal - E-mail: hayet.djelal@unilasalle.fr
} 
from biomass is of major importance. Renewable biomass has a low sulfur content, involves no net release of carbon dioxide, and hence can contribute to sustainable development and environmental preservation (Kasavi et al., 2012), including highervalue chemicals for industrial purposes, as well as liquid fuels for the transportation sector and power.

Four generations of biofuels can be characterized depending on the feedstocks and the conversion technology of the biomass. First generation biofuels are produced from agricultural crops. Second generation biofuels are made from lignocellulosic biomass. Third generation biofuels are produced from algae and fourth generation biofuels use synthetic biology of algae and cyanobacteria (Aro, 2016, Sayed et al., 2017).

Among biofuels, bioethanol properties are compatible with gasoline. According to the Renewable Energy Directive, $10 \%$ of the fuel in 2020 should have a renewable origin. In order to respect the environment and reduce greenhouse gas emissions, microbial pathways can be interesting alternatives to conventional chemical pathways using microorganisms. All fermentable sugars (glucose, sucrose, etc.) can be transformed into bioethanol by fermentation. However, the hydrolysate of lignocellulosic biomass contains mixtures of sugars, pentoses such as xylose and hexoses such as glucose. Xylose is hardly fermented by microorganisms, leading to low efficiency in the production of ethanol (Zabed et al., 2016). Ethanol fuel production involves four stages: (1) the treatment of feedstocks to constitute a solution of fermentable sugars; (2) the biological conversion of sugars into ethanol and $\mathrm{CO}_{2}$ by microorganisms; (3) distilling the ethanol obtained from the fermentation; (4) dehydrating the ethanol to achieve the desired purity (Wheals et al., 1999; Bayrock and Ingledew, 2001; Antoni et al., 2007 ; Cardona and Sanchez, 2007). Using life cycle assessment (LCA), only the third generation of bioethanol from macroalgae biomass presented favorable results (Carneiro et al., 2017).

The use of carbon sources having a low environmental impact for microbial conversion to bioethanol has to be considered (Kasavi et al., 2012). The yield of ethanol production by microbial fermentation depends on the use of an ideal microbial strain, an appropriate fermentation substrate and a suitable process technology (Chniti et al., 2014).

A large variety of microorganisms have the ability to produce ethanol from polysaccharides. But an ideal microorganism used for ethanol production must have rapid fermentative potential, improved flocculating ability, appreciable osmotolerance, enhanced ethanol tolerance and good thermotolerance (Brooks, 2008).

For instance, Saccharomyces cerevisiae (Sheoran et al., 1998), Kluyveromyces marxianus (Limtong et al., 2007), Escherichia coli and Klebsiella oxytocastrain (da Silva et al., 2005), Zymomonas mobilis (Gunasekaran and Raj, 1999), Zygosaccharomyces rouxii and Candida pelliculosa (Chniti et al., 2014) have been studied for ethanol production. Yeasts occur widely in nature and can be recovered from a differing wide range of terrestrial and marine sources. Yeasts can be more or less ubiquitous or they can appear in restricted to very specific habitats (Chandrasena et al., 2006). Among these, more than $95 \%$ of the world production of ethanol by fermentation uses the yeast Saccharomyces cerevisiae and its related species (Russel et al., 1987). Its tolerance to ethanol is one of the main characteristics leading to its selection for alcoholic fermentation (Mobini-Dehkordi et al., 2007; Patruscu et al., 2009). The origin of the S. cerevisiae strain has an importance for the production of ethanol as shown by the study of Shaghaghi-Moghaddam et al. (2017).

Yeast choice has a significant impact on ethanol production profitability and long term viability (Knauf and Kraus, 2006). Yeasts that are tolerant to high temperatures, high ethanol levels and sugar concentrations are therefore very attractive for the fuel alcohol industry (Ylitervo et al., 2011).

Various microorganisms of indigenous strains capable of producing ethanol have been isolated from different local sources such as dates (Djelal et al., 2017), different fruits (Lee et al., 2011), cheese whey (Boudjema et al., 2016), sugar cane and beet molasses (Hamouda et al., 2016). However, strains isolated from the natural substrate gave much better performance than commercial strains (Djelal et al., 2017). It should also be noted that the production of ethanol in cocultures allows higher results than single cultures. For example, the co-immobilization of Saccharomyces cerevisiae and Scheffersomyces stipitis in an immobilized cell reactor increased ethanol production by $10 \%$ compared with a single culture of $S$. cerevisiae (Karagor and Ozkan, 2014). The co-culture of Bacillus amyloliquefaciens and Zygosaccharomyces rouxii from syrup of dates improved the yield of ethanol production by $25 \%$ compared with a single culture of $Z$. rouxii (Djelal et al., 2017). Some studies show a simultaneous improvement of saccharification and bioethanol production from industrial effluent with co-culture of Bacillus subtilis and S. cerevisiae (Tantipaibul et al., 2015), from industrial potato waste with co-culture of Aspergillus niger and $S$. cerevisiae (Izmirlioglu and Demirci, 2016), and from kitchen biowaste with $S$. cerevisiae and Pichia stipitis (Ntaikou et al., 2018)

Several methods can be used for the identification of isolated strains. Matrix-assisted laser desorption ionization-time of flight mass spectrometry (MALDITOF MS) finds a large application in this topic. It is recognized as a powerful, rapid and cost-effective tool 
for the identification of microorganisms (Kudirkien et al., 2015; Girard et al., 2016; Lv et al., 2016). To confirm the obtained result or to refine the identification, it is possible to use conventional molecular biological methods (Gruenwald et al., 2015; Jadhav et al., 2015).

Green algae also contains salts, like sodium chloride, and sulfates from sulfated polymers like ulvan (Holzinger et al., 2015). These components could play a role in the osmotic pressure of the culture medium and hence on ethanol production performance; for green algae salinity is a major abiotic stress in ethanol production via fermentation using yeasts. This has led to research into yeast salt tolerance with the aim of improving ethanol production.

Our study therefore focused on naturally-occurring yeasts that can be grown in sugar based media for alcoholic fermentations and have a high salt tolerance. Therefore, attempts have been made to isolate local yeast strains, to identify them and then to assess their capacity for bioethanol production.

\section{MATERIALS AND METHODS}

\section{Microorganisms, isolation and identification}

For ethanol production, the yeast Saccharomyces cerevisiae CLIB 95 obtained from CIRM (Centre National de Ressources Microbiennes, France) was used in this study. Stock cultures were maintained in an agar medium whose composition was (in g. $\mathrm{L}^{-1}$ ): glucose, 10; peptone, 5; yeast extract, 3 ; malt extract, 3 ; and agar, 15 . Cultures were maintained at $28^{\circ} \mathrm{C}$ for $24 \mathrm{~h}$ and then stored at $4^{\circ} \mathrm{C}$.

Strains were isolated from sugar cane molasses, dates and figs by a serial dilution technique using Yeast Malt Agar (YMA) medium (in g. $\mathrm{L}^{-1}$ ) (yeast extract 3, malt extract 3 , peptone 5 , glucose 10 , agar 15); the $\mathrm{pH}$ was adjusted to 5.5 with $1 \mathrm{~mol} . \mathrm{L}^{-1}$ sulfuric acid. YM medium had the same composition as YMA medium but without agar. Sugar cane molasses was obtained from an Algerian sugar factory (CEVITAL), dates and figs were purchased in a local market. Strains were purified by streaking on YMA; a pure culture of each strain was kept on solid culture medium YMA slats and stored at $4^{\circ} \mathrm{C}$ until needed. For long term conservation, strains were stored in glycerol/YMA medium (20/80 $\%, \mathrm{v} / \mathrm{v})$.

The morphology of cells was examined after culture grown in YM and YMA media, incubated at $30^{\circ} \mathrm{C}$ for 3 days (Kurtzman et al., 2011; Prescott et al., 2010).

The isolated strains were identified by the MALDITOF (VITEK MS) method (Blattel et al., 2013; Moothoo-Padayachie et al., 2013), at LABOCEA (Fougères, FRANCE). To refine the results previously obtained, the strains were also identified by DNA extraction and mini/micro satellite primed PCR. This identification was done in the EQUASA laboratory
(Technopole Brest-IROISE, Plouzane, France), and more information can be found in a previous study (Redou et al., 2015).

The isolated strains were also identified according to their biochemical characteristics using the API 20C test kit (Biomérieux, Marcy l'Etoile, FRANCE).

The composition of the pre-culture medium (inoculum) for yeast was (in g.. $\mathrm{L}^{-1}$ ): glucose, 20; yeast extract, 10; and peptone, 10 . The cells were cultivated in a sterilized culture medium in $250 \mathrm{~mL}$ Erlenmeyer flasks (working volume $25 \mathrm{ml}$ ) at $28^{\circ} \mathrm{C}$, on a rotating shaker (INNOVA 40) at $180 \mathrm{rpm}$ for $18 \mathrm{~h}$ in order to obtain high cell density. Then, the cells were harvested aseptically by centrifugation $\left(1,800 \mathrm{~g}, 4^{\circ} \mathrm{C}\right.$ and 5 $\mathrm{min})$, re-suspended in $25 \mathrm{~mL} \mathrm{KCl}(150 \mathrm{mM})$ and then centrifuged again in similar conditions. The suspension obtained after harvesting cells and re-suspending in $10 \mathrm{~mL}$ of $150 \mathrm{mM} \mathrm{KCl}$ was used as inoculum for the experiments.

\section{Characteristics of fermentation}

The fermentation of glucose, galactose, fructose, saccharose, lactose, xylose, maltose and arabinose was tested. The sugars were dissolved at $2 \%(\mathrm{w} / \mathrm{v})$ in the Wikerham medium (Djelal et al., 2012) containing in g.L. ${ }^{-1}$ : Peptone 10, yeast extract 5, phenol red $24 \mathrm{mg}$. The tests were performed in Durham tubes, which were inoculated and incubated at $30^{\circ} \mathrm{C}$ for three weeks. The tests were performed at least in duplicate.

The tolerance to salinity was carried out using the Yeast Malt (YM) medium, to which were added different concentrations of $\mathrm{NaCl}(0.5,1.0$ and $1.5 \mathrm{M})$. The cultures were incubated at $30^{\circ} \mathrm{C}$ for $72 \mathrm{~h}$ and the Optical Density (OD) was measured every $24 \mathrm{~h}$ at 620 $\mathrm{nm}$ to follow yeast growth (Abdel and Moghaz, 2010).

The isolated strains were inoculated in $10 \mathrm{~mL}$ of Tryptone Glucose Yeast Extract Agar medium (TGY) for testing ethanol tolerance. Its composition was (in g.L.-1): yeast extract, 5; glucose, $1 ; \mathrm{K}_{2} \mathrm{HPO}_{4}$, 1, agar, 2 and the $\mathrm{pH}$ was adjusted to 7 . Different concentrations of ethanol were studied $(5,7,9,10,12,14,16$ and $20 \%$ ). The tubes were incubated at $28{ }^{\circ} \mathrm{C}$ for $48 \mathrm{~h}$. After incubation, the viability of yeast cells were checked by serial dilutions with sterile distilled water and plated on agar medium; the ethanol tolerance was selected based on the growth performance.

The isolated strains were tested for their ability to produce ethanol on glucose substrate $\left(30 \mathrm{~g} . \mathrm{L}^{-1}\right)$; the strains were inoculated at $1 \%(\mathrm{v} / \mathrm{v})$ into $250 \mathrm{ml}$ hermetic bottles containing $100 \mathrm{ml}$ of the fermentation medium, which was prepared following the method described by Djelal et al. (2006) and peptone (5 g.L-1) was used as nitrogen source.

Synthetic medium is formed by a single sugar (glucose, 15 g.L.- - $^{-1}$ and salts $(\mathrm{NaCl} 1.37 \mathrm{M}$ ) at levels close to those of green algae. This medium was prepared as 
described earlier in this paper. This synthetic medium was used to demonstrate the influence of salts on the activities of strains.

Ethanol fermentation was carried out in $250 \mathrm{~mL}$ hermetic bottles, on a rotating shaker (INNOVA 40), at $180 \mathrm{rpm}, 28^{\circ} \mathrm{C}$, during $48 \mathrm{~h}$. Inoculation levels were $1 \%(\mathrm{v} / \mathrm{v})$. Experiments were performed at least in duplicate, and samples were withdrawn and centrifuged at $1,800 \mathrm{~g}, 4^{\circ} \mathrm{C}$ and $5 \mathrm{~min}$. The cell free supernatant was evaluated for ethanol and sugar concentrations.

\section{Analytical methods}

Analyses of the various metabolites produced by the yeasts and the sugar concentrations were performed by high performance liquid chromatography (HPLC); analysis was conducted using an ion exclusion column HPX-87H $(300 \times 7.8 \mathrm{~mm}$, Bio-Rad, Hercules, CA, USA), kept at $45^{\circ} \mathrm{C}$ (Oven CrocoCil ${ }^{\mathrm{TM}}$; CluzeauInfo-labo, Ste Foy LaGrande, France). The eluent for separation was sulfuric acid $(0.01 \mathrm{M})$, applied at a flow rate of $0.7 \mathrm{~mL} \cdot \mathrm{min}^{-1}$. The column was coupled with a Shimadzu RIO-6A Refractive index index Detector (Japan), which was used for the detection of the various compounds (Djelal et al., 2005).

Cell growth was deduced from turbidimetric measurements made using a spectrophotometer (SECOMAM, Ales, France) at $600 \mathrm{~nm}$. The measurements were performed directly after the sampling and after centrifugation at $3000 \mathrm{rpm}, 4^{\circ} \mathrm{C}$ and $5 \mathrm{~min}$; the difference between the two values represented cell growth. The $\mathrm{pH}$ was adjusted to $6(\mathrm{pH}$ meter WTW pH 315i) by addition of sterile $2 \mathrm{mmol}^{-L^{-1}}$ $\mathrm{KOH}$.

\section{Fermentation efficiency}

During alcoholic fermentation, the fermentable sugars are converted into ethanol and carbon dioxide by the action of microorganisms.

The overall chemical formula for alcoholic fermentation, for example in the case of glucose as the main carbon substrate, is the following (Equation 1):

$\mathrm{n} \times\left(\mathrm{C}_{6} \mathrm{H}_{12} \mathrm{O}_{6}\right) \rightarrow 2 \mathrm{n} \times\left(\mathrm{C}_{2} \mathrm{HO}_{5} \mathrm{H}\right)+2 \mathrm{nCO}_{2}$

According to Equation (1), for a total conversion, one mole of glucose leads to two moles of ethanol and two moles of carbon dioxide. The ethanol theoretically produced can therefore be calculated as follows (Equation 2):

$[\text { Ethanol }]_{\text {theor }}\left(\mathrm{g} \cdot \mathrm{L}^{-1}\right)=2 \times[$ glucose $] \times\left(\frac{\mathrm{M}_{\text {ethanol }}}{\mathrm{M}_{\text {glu cose }}}\right)$

The yield of ethanol to consumed sugar $(\mathrm{g} / \mathrm{g})$ was defined as (Equation 3):
Yield of ethanol $\left(\mathrm{g} \cdot \mathrm{g}^{-1}\right)=\frac{[\text { ethanol }]}{\text { sugar consumption }}$

The ethanol productivity $\left(\mathrm{g} \cdot \mathrm{L}^{-1} \cdot \mathrm{h}^{-1}\right)$ was calculated as the ratio of ethanol concentration (g. $\left.\mathrm{L}^{-1}\right)$ at the fermentation time $(t, h)$ (Equation 4$)$ :

Ethanol productivity $\left(\mathrm{g} \cdot \mathrm{L}^{-1} \cdot \mathrm{h}^{-1}\right)=\frac{[\text { ethanol] }}{\text { time }}$

and fermentation efficiency was calculated according to Equation 5:

Efficiency $(\%)=\frac{\text { Pratical yield of ethanol }}{\text { Theoretical yield }} \times 100$

\section{RESULTS AND DISCUSSION}

Three yeasts were selected from isolates from molasses, dates and figs ; they were codified as strains $\mathrm{S} 1, \mathrm{~S} 2$ and $\mathrm{S} 3$ respectively.

\section{Morphological characterization}

Cell morphology was observed under a Carl Zeiss Axiostar Microscope X40 (a, c, and e) and X1000 (b, $\mathrm{d}, \mathrm{f}$ ) (Figure 1). The isolated yeasts did not show any variation according to their shape, color, margin and surface. The appearance of the selected yeast on YMA was smooth colonies white in color, and shiny surfaces. The microscopic characteristics included oval cells with budding. This is in agreement with the literature, since the same morphological characteristics were observed for yeasts isolated from sugar cane molasses (Hamouda et al., 2016), pineapple (Patil and Patil, 2010), and orange from the greater Mekong subregion (Techaparin et al., 2017). Indeed, it is well known that yeast is ubiquitous and can grow on different substrates (Tikka et al., 2013).

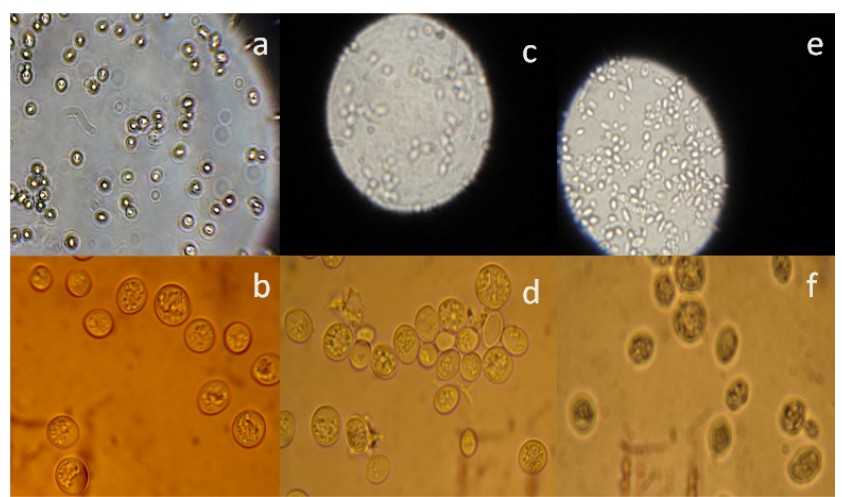

Figure 1. Morphology of the yeast strains S1 (a) (b), S2 (c) (d), S3 (e) (f).

\section{Identification of strains}

According to the morphological and biochemical characteristics, all isolated strains seem to be yeasts. 
Identification of the three isolated strains using MALDI-TOF MS was performed. Information provided by this analysis showed that the studied strains were Saccharomyces cerevisiae with a percentage of identification above $99 \%$. To confirm this result and to check the similitude between the isolated strains, a polymerase chain reaction (PCR) was carried out. Thereby, Mini/Micro-Satellite Primed PCR analysis was realized on the 3 strains isolated (S1, S2, S3) and a control (Saccharomyces cerevisiae DSM70449). On the basis of the genetic profiles, the GelJ software was used to produce a dendrogram specifying the similarity to the control strains. The $S$. cerevisiae strains S2 and S3 where very similar ( $80 \%$ similar), whereas the Saccharomyces cerevisiae S1 strain belonged to a separate group.

The biochemical test dealing with the assimilation of carbohydrates (API 20C test kit, Biomérieux, Marcy l'Etoile, France) was also in favor of Saccharomyces species.

\section{Characteristics of fermentation}

Sugar fermentation test

The ability of the isolated strains to ferment various sugars such as glucose, galactose and other ones was examined. As observed, all isolates were able to ferment glucose, galactose, sucrose, maltose and fructose; while the other ones (lactose, xylose and arabinose) were not fermentable (Table 1). The importance of this characterization is related to the interest of industries in obtaining strains capable of fermenting several sugars other than glucose (Bai et al., 2008). This is due to the environmental and seasonal variations in the composition and amount of sugars found in the Ulva. This characterization has been developed in other studies and they found that their wild-type of $S$. cerevisiae can use several sugars, such as maltose, sucrose, glucose, mannose, fructose and galactose, but not xylose and arabinose (van Maris et al., 2006). Walker and Wilson (1991) reported that all isolated yeasts ferment at least one type of sugar. However, a majority of these isolates, which ferment glucose, galactose, maltose, sucrose and raffinose, belonged to the genus $S$. cerevisiae (Dash et al., 2015).

\section{Salinity tolerance test}

The osmotic pressure caused by high concentrations of salts in the medium affects significantly the viability and cell growth of several microorganisms. This influence depends on the type and species of microorganisms. The obtention of strains tolerant to salts could overcome the limitation encountered during the fermentation and the production of ethanol. In order to determine the efficiency of the isolated strains to tolerate salinity, they were inoculated in liquid YM without salt and with different salinities (between 0.5 $\mathrm{M}$ and $1.5 \mathrm{M}$ of $\mathrm{NaCl}$ ). As observed, the presence of the salt in the medium reduced significantly the growth of the isolated strains (Figure 2). The decrease in growth cell was $70.5 \%, 60.8 \%$ and $61.32 \%$ for strains $\mathrm{S} 1$, $\mathrm{S} 2$ and $\mathrm{S} 3$, respectively, in the presence of $0.5 \mathrm{M}$ salt. The growth of the strains decreased upon increasing the salt concentration to reach $85.7 \%, 74.09 \%$ and $73.05 \%$ for strains S1, S2 and S3, respectively, in the presence of $1.5 \mathrm{M}$ salt. However, the presence of salt induces an energy consumption by the strains for their

Table 1. Fermentation of different carbohydrates by selected isolated strains.

\begin{tabular}{|c|c|c|c|c|c|c|c|c|}
\hline & glucose & galactose & sucrose & lactose & fructose & xylose & maltose & arabinose \\
\hline S1 & + & + & + & - & + & - & + & - \\
\hline $\mathrm{S} 2$ & + & + & + & - & + & - & + & - \\
\hline S3 & + & + & + & - & + & - & + & - \\
\hline
\end{tabular}

+ : Change in color and gas production, -: no change.
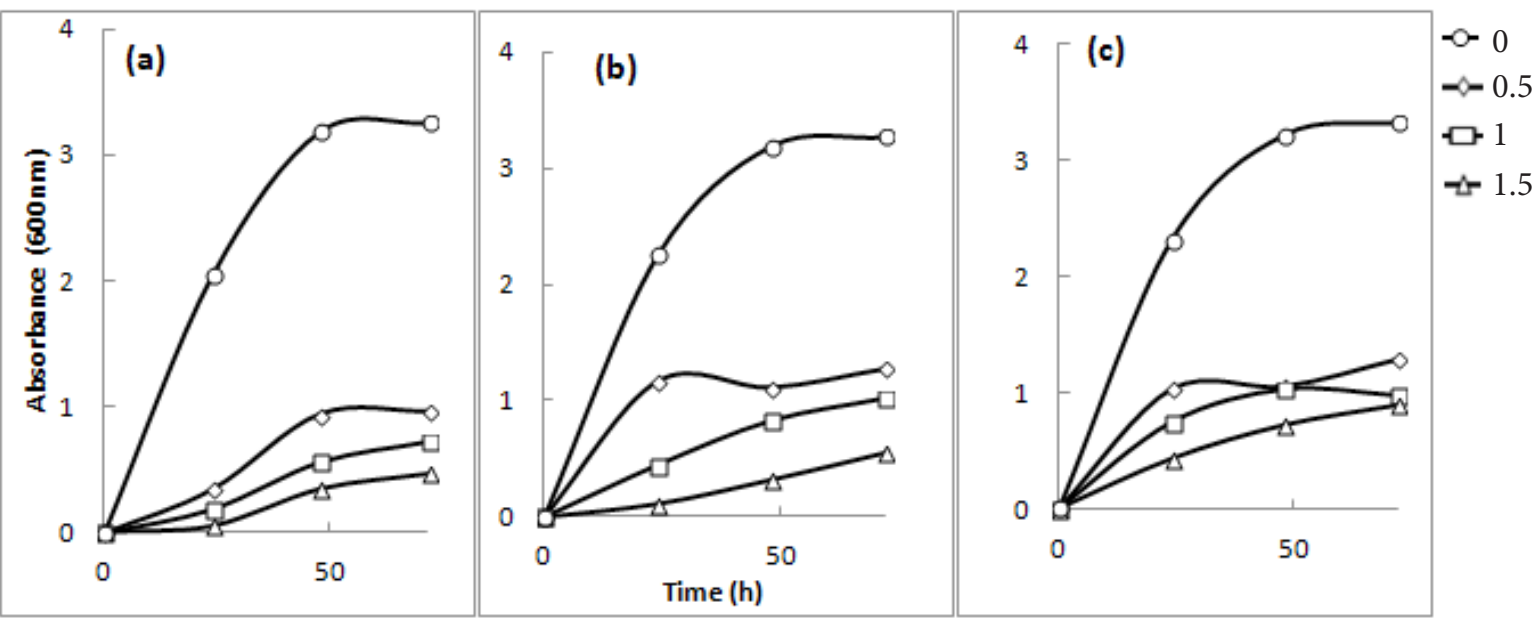

Figure 2. Absorbance of the three isolated strains in increasing salt concentrations (M). (a) S1, (b) S2, (c) S3. 
maintenance rather than for their growth. Indeed, the maintenance of the ionic equilibrium within the cell is the most energy-consuming. The study of Wastson (1970) shows that increasing the salinity of the culture medium in $S$. cerevisiae results in an increase in maintenance energy. The holding energy was multiplied by 4 when $1 \mathrm{M}$ of $\mathrm{NaCl}$ was added to the culture medium and the growth of $S$. cerevisiae was consequently affected.

It can also be seen from these results that the isolated strains have a tolerance to high salt concentrations, given their ability to survive and grow. Similar results were observed in several studies. For example, Babu and Ilyas (2017) isolated a Saccharomyces cerevisiae strain from mangrove sediment that tolerates salinity in the range from 0.5 to $1.5 \mathrm{M}$ of $\mathrm{NaCl}$. Shaghaghi-Moghaddam et al. (2018) observed that the industrial strain of $S$. cerevisiae had higher resistance against osmotic pressure of the fermented broth than the traditional baker's yeast strain. These results are encouraging and they allow studying later the capacity of these strains to tolerate different concentrations of ethanol.

\section{Ethanol tolerance test}

The capability to tolerate various stresses (osmolarity and ethanol) is one of the main criteria to select strains for efficient ethanol fermentation. The common challenge of strains can be overcome by using ethanol-tolerant yeasts and hence the selection of strains with high resistance to ethanol is important. The ethanol tolerance capacity depends on the type of strain. To evaluate the ethanol tolerance capacity, the isolated strains were inoculated in the TGY medium containing different concentrations of ethanol $(5,7,9$, $10,12,14,16$ and $20 \%(\mathrm{v} / \mathrm{v}))$.

Table 2 represents the effect of increasing concentrations of ethanol on the different strains as compared to $S$. cerevisiae CLIB 95 as reference. The results showed that all strains grew at 5, 7, 9, 10 and $12 \%$ ethanol concentration. Above this concentration, no growth was observed for the reference strain; ethanol inhibits the yeast growth, the cell division, and decrease the cell volume and the specific growth rate, and high concentrations reduce cell vitality

Table 2. Ethanol tolerance of the isolated strains.

\begin{tabular}{ccccc}
\hline $\begin{array}{c}\text { Ethanol } \\
\text { concentration (\%) }\end{array}$ & S1 & S2 & S3 & $\begin{array}{c}\text { S. } \\
\text { cerevisiae }\end{array}$ \\
\hline 5 & + & + & + & + \\
7 & + & + & + & + \\
9 & + & + & + & + \\
10 & + & + & + & + \\
12 & + & + & + & + \\
14 & W & + & + & - \\
16 & - & + & + & - \\
20 & - & + & + & - \\
\hline
\end{tabular}

+: Positive; -: Negative; W: Weakley positive. and increase cell death (Birch and Walker, 2000). Regarding the isolated strains, S1 tolerated up to $14 \%$ $(\mathrm{v} / \mathrm{v})$ of ethanol, while interestingly the isolates $\mathrm{S} 2$ and S3 were highly tolerant, up to $20 \%$ (v/v) ethanol.

Resistant strains can be isolated from natural resources like fruits and animals, and the differences in ethanol tolerance might be due to differences in their natural habitat. Negi et al. (2013) isolated strains from different parts of Himachal Pradesh in India. From the 14 strains that have been identified as $S$. cerevisiae, only one tolerated up to $12 \%(\mathrm{v} / \mathrm{v})$ ethanol. The ethanol tolerance showed by the strains isolated in this study was consistent with those of Nwachukwu et al. (2006) who found a maximum and minimum ethanol tolerance of $20 \%$ and $10 \%(\mathrm{v} / \mathrm{v})$ for their strains. However, medium enrichment with soybean or palm kernel enhanced the ethanol tolerance. Maximum tolerance increased from 20 to $22 \%(\mathrm{v} / \mathrm{v})$ ethanol and minimum tolerance increased from 10 to $15 \%(\mathrm{v} / \mathrm{v})$ ethanol (Osho, 2005). Among 234 yeast isolates, Techaparin et al. (2017) found that the majority of the isolates tolerated ethanol concentrations up to $10 \%(\mathrm{v} / \mathrm{v})$. Interestingly, five isolated yeasts were highly tolerant to ethanol concentrations up to $13 \%$ (v/v). A study on the screening of $S$. cerevisiae for high tolerance to ethanol showed that the tolerance was doubled for strains irradiated with gamma rays compared to the use of the initial S. cerevisiae strain (Mehdikhani et al., 2011). An ethanol-tolerant strain may exhibit an ability to resist osmotic stress. This was demonstrated by Osho (2005) for their 4 strains, isolated from fermenting cashew apple juice, which showed measurable growth in medium containing 9\% (v/v) ethanol and can tolerate up to $25 \%(\mathrm{w} / \mathrm{v})$ glucose. The use of efficient yeast strains with high ethanol tolerance to improve ethanol yields in the fermentation product (cane molasses) would reduce distillation costs and hence the profitability of the overall process (Chandrasena et al., 2006).

\section{Fermentation \\ Ethanol production in synthetic medium}

The ethanol production of the isolated strains in the culture medium containing 30 g. $\mathrm{L}^{-1}$ of glucose was examined after incubation at $28^{\circ} \mathrm{C}$ for $46 \mathrm{~h}$ in order to select strains that have the ability to produce ethanol at important concentrations. In view making of comparison, S. cerevisiae CLIB 95 was considered as a reference.

The strains presented practically the same fermentative capacity. Comparing cell growth displayed in Figure (3, A), all the strains led to the same highest cell growth and the same final amount of biomass. There were no significant differences regarding glucose consumption and ethanol production (about 12 g. $\mathrm{L}^{-1}$ of ethanol for the strains). Yeast strains also secreted 


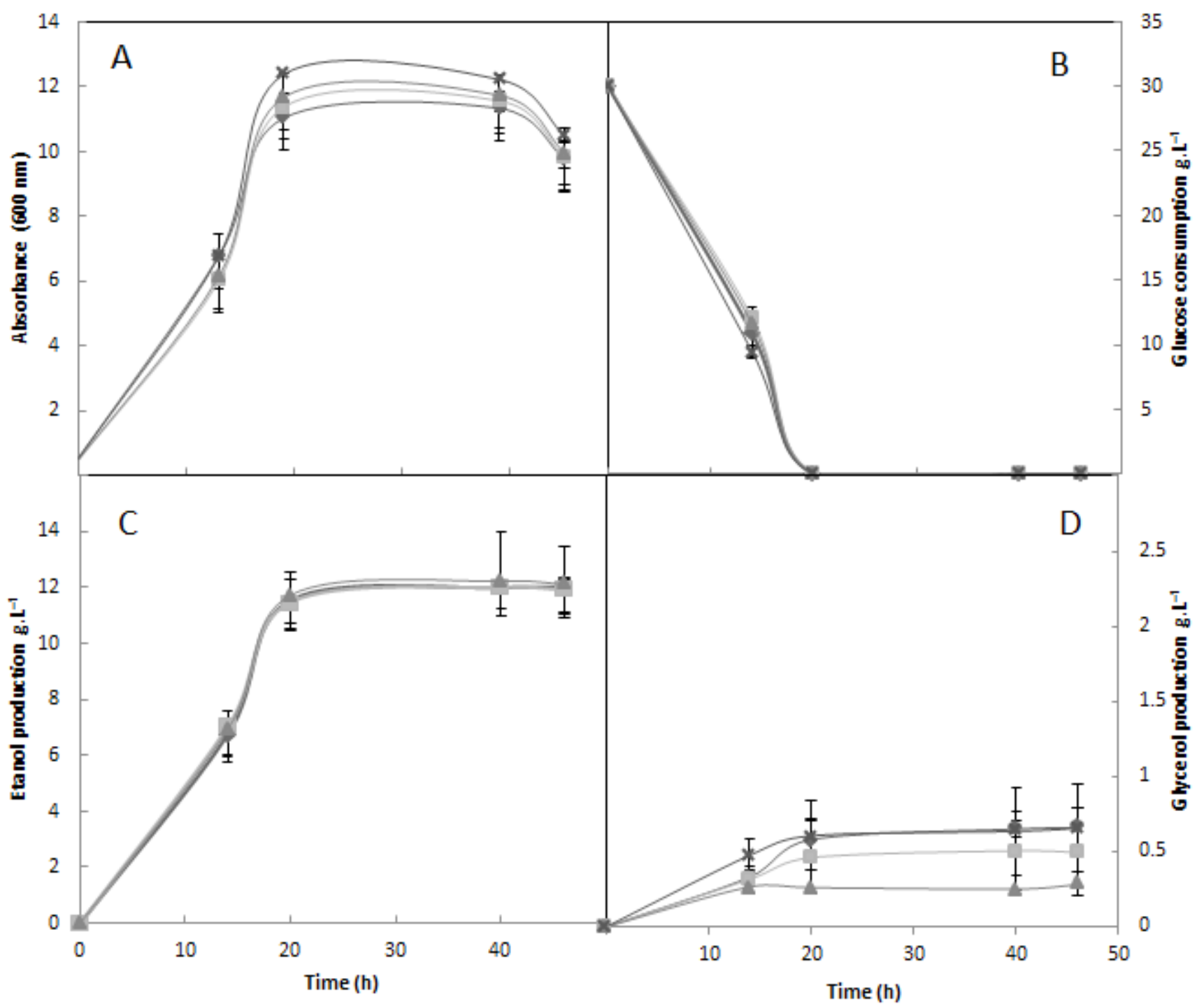

Figure 3. Absorbance (A), glucose consumption (B), ethanol production (C) and glycerol production (D) timecourses during growth of the strains S1 $\left(^{\star}\right)$, S2 $\left(^{-}\right), \mathrm{S} 3\left(^{-}\right)$, and $\left(^{*}\right)$ S.cerevisiae in synthetic medium containing glucose $\left(30\right.$ g.L $\left.\mathrm{L}^{-1}\right)$ as carbon substrate.

glycerol during fermentation (Figure 3, D). S1 was the lowest producer of glycerol $\left(0.28\right.$ g.L $\left.\mathrm{L}^{-1}\right)$, while $\mathrm{S} 3$ and the strains of reference produced the highest concentrations of glycerol $\left(0.66 \mathrm{~g} . \mathrm{L}^{-1}\right)$. Ethanol yields at $20 \mathrm{~h}$ of fermentation were $0.38-0.39$ g.g ${ }^{-1}$ for all strains and the productivities were almost $0.58 \mathrm{~g} \cdot \mathrm{L}^{-1} \cdot \mathrm{h}^{-1}$.

Techaparin et al. (2017) tested the ethanol production of the selected thermotolerant yeast strains isolated using glucose as substrate and showed that all the twenty-six strains tested produced ethanol; the ethanol concentrations, productivities and yields were in the range $37.47-72.69$ g. $\mathrm{L}^{-1}, 0.78-1.59 \mathrm{~g} . \mathrm{L}^{-1} \cdot \mathrm{h}^{-1}$ and 0.27-0.44 g.g ${ }^{-1}$, respectively. Dash et al. (2015) also investigated the ethanol production ability of some isolated strains on different natural substrates, like sugarcane juice, Mahua flower juice, or grape juice; all the strains produced ethanol, but the fermentation ability varied greatly with the substrate used. Brooks
(2008) screened the ability of their isolated strains to produce ethanol by using the banana peel-yeast extract peptone fermentation medium, supplemented with $10 \%(\mathrm{w} / \mathrm{v})$ glucose. It was found that all the strains produced ethanol, but the ethanol production capacity depended on the fermentation medium and the strains.

The strains presented practically the same fermentative capacity; consequently, all strains were considered for subsequent experiments.

Ethanol production in synthetic model medium of macro-algae

After the examination of the tolerance of the strains to salinity and their ability to produce ethanol,

fermentation of these strains on synthetic medium of algae was carried out.

This medium contained salts which could influence the strain's performances by their impact on the 
osmotic pressure. The supplementation of synthetic medium (15 g. L $^{-1}$ glucose) with sodium chloride at concentrations similar to those found in hydrolysates (1.37 $\mathrm{M} \mathrm{NaCl}$, data not shown) should allow the study of ethanol production of the three selected yeast strains facing this change of osmolality.

Ethanol production and glucose consumption were observed for the three isolated strains and the strain of reference in the culture medium (Table 3 ).

After $46 \mathrm{~h}$ of fermentation, almost all the glucose was consumed; the consumption rate was very slow during the first day of culture and then increased compared to the basic medium $\left(30\right.$ g. $\mathrm{L}^{-1}$ of glucose without salts); modified medium with higher levels of salinity is a source of osmotic stress (Djelal et al., 2005), illustrated by the lower rates observed for glucose consumption, since total consumption of 30 g. $\mathrm{L}^{-1}$ glucose was observed in only about one day in the absence of salts. It was in accordance with the biomass decrease in the presence of salts, since maximum cell density (absorbance at $600 \mathrm{~nm}$ ) was in the range 11-13 (Figure 3 ) in the absence of salts and only in the range 1.3-1.9 in the presence of salts (Table 3). Osmotic pressure impedes yeast development and thus partially inhibits glucose assimilation (Djelal et al., 2012). A high osmotic pressure drives a passive water outflow through the cytoplasmic membrane to restore thermodynamic equilibrium, thus to a dehydratation (Blomberg, 2000). Similar behavior was previously observed with Hansenula anomala (Djelal et al., 2006), Pichia farinosa (Vijaikishore and Karanth, 1984) and Dekkera bruxellensis (Galalafassi et al., 2013). Despite the presence of a high amount of salt, the strains still produced ethanol. This is encouraging for future work on algal hydrolysates. The highest ethanol production was observed for the strains S2 and S3 (3.8 and 3.9 g. $\mathrm{L}^{-1}$ respectively), while S1 and $S$. cerevisiae produced the lowest amounts of ethanol (2.2 and 2.1 g.L $L^{-1}$ respectively); this should be related to the sensitivity of this strain to the osmotic pressure. It is widely reported that $\mathrm{NaCl}$ has an inhibitory effect on ethanol production (Djelal et al., 2005). This loss of ethanol production should be balanced by a rise of glycerol production. The strain57s tried to lowered osmotic potential of the cytoplasm and re-entry of some of the lost water by the production of glycerol $\left(0.2 \mathrm{~g} \cdot \mathrm{g}^{-1}\right)$. Concerning acetic acid, similar yields were found for the strains $\left(0.05 \mathrm{~g} \cdot \mathrm{g}^{-1}\right)$. Like glycerol, acetic acid also plays a role in osmoregulation (Blomberg and Adler, 1989; Blomberg and Adler, 1992). The three strains S1, S2 and S3 isolated from sugar cane molasses, dates and figs, respectively, showed some differences regarding tolerance to salt, especially at the level of ethanol yield produced $(0.16$ for $\mathrm{S} 1$, 0.27 and 0.29 g. $\mathrm{g}^{-1}$ respectively for S2 and S3) and the fermentation efficiency (32\% for S1, 52 and $58 \%$ for S2 and S3). Regarding the osmotolerance of their strains isolated from pineapple and orange, Nasir et al. (2017) found that the strain isolated from pineapple successfully tolerated up to $9 \%$ sodium chloride salt, while the other strain showed high growth up to $12 \%$ sodium chloride salt concentration.

Also by comparing the three isolated strains with the reference strain, it can be observed that the strain $\mathrm{S} 1$ gave results very close to those of $S$. cerevisiae whereas S2 and S3 exhibited a better fermentation capacity in the presence of these stressful conditions. The microorganisms which are capable of producing ethanol, especially under stress conditions (temperature, osmolarity, ethanol tolerance), have been strains isolated from various sources. This is in agreement with the study of Ramos et al. (2013), who evaluated the fermentative performances in sugarcane juice of 66 indigenous Saccharomyces cerevisiae strains in stressful conditions (temperature, osmolarity, sulfite and ethanol tolerance). They observed that highest values of $Y_{\mathrm{p} / \mathrm{s}}$ in sugarcane juice; fermentation was obtained with four strains, one isolated from fruit $(0.46)$ and the others from sugar cane $(0.45,0.44$ and $0.43)$, and these values were higher than the value obtained using traditional yeast (0.38).

\section{Co-culture of S2 and S3}

Co-culture bioconversion provides the opportunity to maximize substrate utilization rate, increase ethanol yield and production rate and reduce process costs (Singh and Bishnoi, 2012; Chen, 2011). To check if co-culture enhances the ethanol production, an assay was made in the same conditions of the mono-culture, namely 15 g. $\mathrm{L}^{-1}$ glucose and $1.37 \mathrm{M} \mathrm{NaCl}$. The S2 and S3 strains were chosen for their tolerance to salts and ethanol production. The same amount of each strain was used in the fermentation $(50 \% / 50 \%(\mathrm{v} / \mathrm{v}))$. The total volume of the inocula was $1 \%$ in the experiments. Co-

Table 3. Comparison of consumption and production between the three isolated strains after $46 \mathrm{~h}$ of fermentation in algae synthetic medium (15 g. $\mathrm{L}^{-1}$ glucose and $\left.1.37 \mathrm{M} \mathrm{NaCl}\right)$.

\begin{tabular}{|c|c|c|c|c|c|c|c|}
\hline & $\begin{array}{c}\text { Glucose } \\
\text { consumption }\end{array}$ & $\begin{array}{c}\text { Ethanol } \\
\text { production }\end{array}$ & \multirow{2}{*}{$\begin{array}{c}\text { Efficiency } \\
(\%)\end{array}$} & \multirow{2}{*}{$\begin{array}{c}\text { Absorbance } \\
\text { (at 600nm) }\end{array}$} & $\begin{array}{c}\text { Ethanol } \\
\text { yield }\end{array}$ & $\begin{array}{c}\text { Glycerol } \\
\text { yield }\end{array}$ & $\begin{array}{c}\text { Acetic acid } \\
\text { yield }\end{array}$ \\
\hline & \multicolumn{2}{|c|}{$\left(\right.$ g. $\left.L^{-1}\right)$} & & & & $\left(\mathrm{g} . \mathrm{g}^{-1}\right)$ & \\
\hline $\mathrm{S} 1$ & 13.80 & 2.30 & 32 & 1.53 & 0.16 & 0.21 & 0.04 \\
\hline $\mathrm{S} 2$ & 14.26 & 3.68 & 52 & 1.89 & 0.27 & 0.19 & 0.05 \\
\hline S3 & 12.88 & 3.68 & 58 & 1.89 & 0.29 & 0.20 & 0.05 \\
\hline S.cerevisiae & 13.34 & 2.30 & 31 & 1.33 & 0.16 & 0.20 & 0.03 \\
\hline
\end{tabular}


culture led to an improvement of ethanol yield and the efficiency of fermentation compared to monoculture fermentation. Figure 4 shows that the growth in coculture is more important than in single culture. This growth was related to the consumption of glucose. In fact, it can be observed in Figure 5 that the use of the consortium is more effective for the production of ethanol. Indeed, it was observed that, after $24 \mathrm{~h}$, the consumption of glucose for the strains S1 and S2 was 2 and 4 g.L. ${ }^{-1}$, respectively (Figure 5). However, the consumption of glucose in the case of a consortium was doubled to $7 \mathrm{~g}$ g. $\mathrm{L}^{-1}$. This leads to a cumulative ethanol production of 2.5 g.L. $\mathrm{L}^{-1}$. These results show that the strains did not adversely affect the production of ethanol as well as their growth (Figure 4).

The effect of the change in the size of the inoculum for each strain relative to the co-culture ( 0.5 instead of 1) did not affect their fermentative capacity.

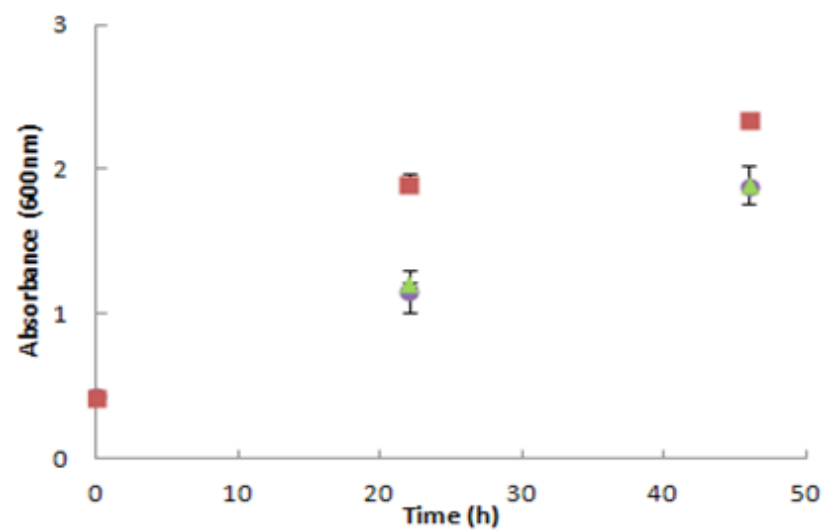

Figure 4. Absorbance at $600 \mathrm{~nm}$ measured during $46 \mathrm{~h}$ of fermentation by S2S3 (red), S2 (violet) and $\mathrm{S} 3$ (green), in the synthetic model medium (15 g. $\mathrm{L}^{-1}$ glucose and 1.37 mol. $\mathrm{L}^{-1} \mathrm{NaCl}$ ).

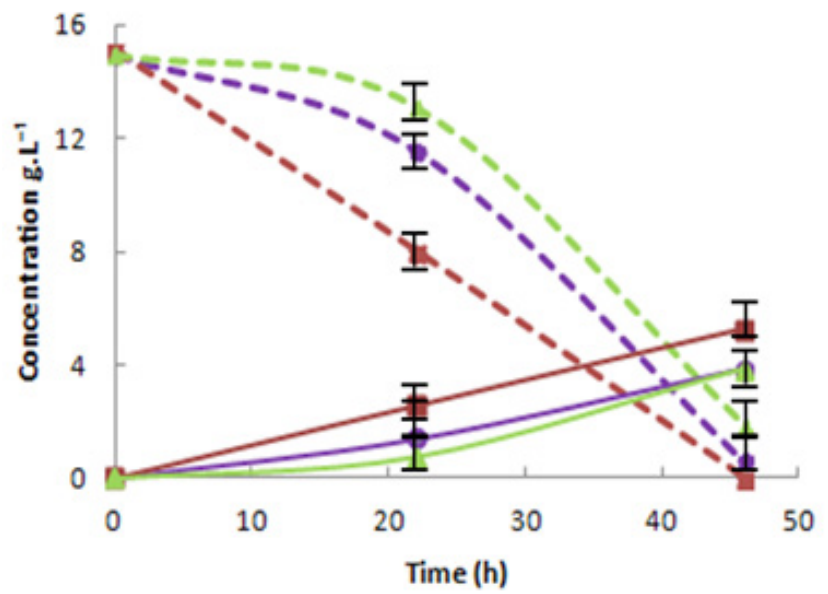

Figure 5. Kinetics of glucose consumption (dashed line) and ethanol production (continuous line) for the three isolated strains S2S3 (red), S2 (violet), S3 (green) in synthetic model medium of algae (15 g.L $\mathrm{L}^{-1}$ glucose and 1.37 mol. $\mathrm{L}^{-1} \mathrm{NaCl}$ ).
Ethanol yields were $0.35 \mathrm{~g} . \mathrm{g}^{-1}$ for the co-culture and 0.27 and $0.29 \mathrm{~g}^{-\mathrm{g}^{-1}}$ for the pure cultures of S2 and S3, respectively (Figure 6).

Concerning efficiency, it increased from 52 and $59 \%$ for S2 and S3, respectively, in the monoculture to $68 \%$ in the co-culture of S2 and S3. Djelal et al. (2017) showed that the fermentation of by-products of dates by co-cultures of the isolated strain B. amyloliquefaciens and $Z$. rouxii showed an increase of the yield of ethanol by $12.5 \%$ compared with the single culture; they also demonstrated that the strain ratio did not affect the results of ethanol productivity. Kalyani et al. (2013) observed that the co-culture of S. cerevisiae and Pichia stipitis produced $23 \%$ and $38 \%$ more ethanol than the amounts produced by $S$. cerevisiae and P. stipitis in pure cultures. Harish et al. (2010) obtained an ethanol yield of $0.41 \mathrm{~g} . \mathrm{g}^{-1}$ during the co-culture of Clostridium thermocellum and Clostridium thermosaccharolyticum on banana waste hydrolysate, namely 36 to $59 \%$ more than the corresponding pure culture of Clostridium thermocellum. These promising results show that coculture has great potential for efficient conversion of medium rich in salt, like green macro-algae (Chaetomorpha linum), to ethanol.

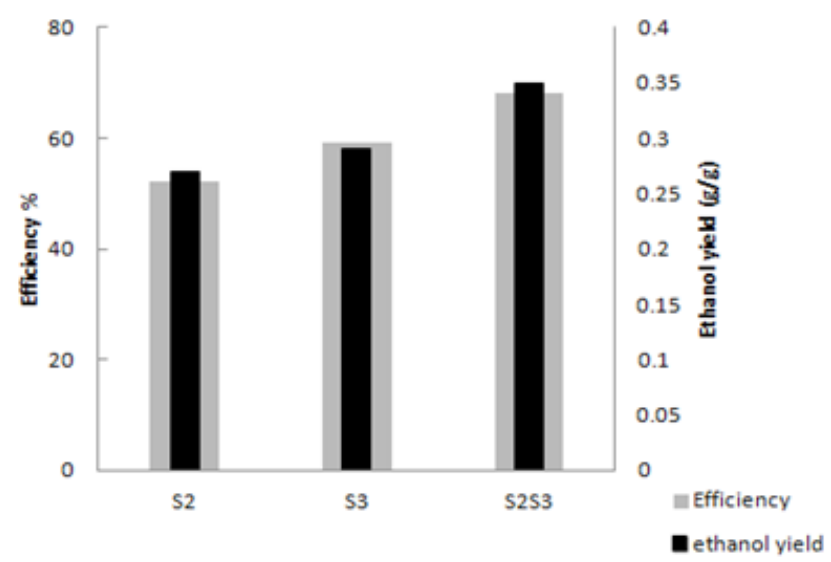

Figure 6. Comparison of ethanol yield (black bars) and efficiency (gray bars) during single cultures of S2, $\mathrm{S} 3$ and their co-culture in synthetic model medium of algae (15 g.L $\mathrm{L}^{-1}$ glucose and $\left.1.37 \mathrm{~mol} . \mathrm{L}^{-1} \mathrm{NaCl}\right)$.

\section{CONCLUSION}

In the present research work, three yeast strains, $\mathrm{S} 1$, $\mathrm{S} 2$ and $\mathrm{S} 3$, isolated from sugarcane molasses, dates and figs, respectively, were characterized by conventional morphological and biochemical methods. The strains showed tolerant characteristics to stressful conditions; they tolerated up to 1.5 mol. $\mathrm{L}^{-1} \mathrm{NaCl}$. All the strains were able to produce ethanol. The strains $\mathrm{S} 2$ and S3 showed very high ethanol tolerance $(20 \%(\mathrm{v} / \mathrm{v}))$ compared to a commercial yeast strain of $S$. cerevisiae and the strain S1, which tolerated up to $14 \%(\mathrm{v} / \mathrm{v})$ of ethanol. Thus, S2 and S3 could serve as potential 
strains for ethanol fermentation under high osmotic pressure. Co-culture of S2 and S3 enhanced the ethanol production by increasing the yield of ethanol by $12.5 \%$ compared to the single culture. The strains were identified as species of S.cerevisiae, and S2 and S3 were very similar ( $80 \%$ similarity). Therefore, studying the biodiversity of yeasts from different environmental media may reveal very similar strains, with the desired characteristics for fermentation under stressful conditions.

\section{ACKNOWLEDGEMENTS}

The authors want to thank Christophe Le Meur and Gaetan Burgaud from ESIAB. Technopôle BrestIroise - Parvis Blaise Pascal - 29280 Plouzane, France, for the identification of the three strains by PCR, they also want to thank the Lebanese University for the $\mathrm{PhD}$ fellowship of Walaa Sayed.

\section{REFERENCES}

Abdel, A. and Moghaz, E. Comparative Study of salts Tolerance in Sccharomyces cerevisiae and Pichia pastoris yeast strains. Advances in Bioresource, 1, 169-176 (2010).

Antoni, D., Zverlov, V.V. and Schwarz, W. H. Biofuels from microbes, Applied Microbiology Biotechnology, 77, 23-35 (2007). https://doi. org/10.1007/s00253-007-1163-x

Aro, E.M. From first generation biofuels to advanced solar biofuels, Ambio, 45, 24-31 (2016). https:// doi.org/10.1007/s13280-015-0730-0

Babu, M.P. and Ilyas, M.M. SCP production from Saccharomyces cerevisiae isolated from mangrove sediment. International Journal Advanced Multidisciplinary Research, 4, 1-10 (2017). https:// doi.org/10.22192/ijamr.2017.04.01.001

Bai, F.W., Anderson, W.A. and Moo-Young, M. Ethanol fermentation technologies from sugar and starch feedstocks. Biotechnology Advanced, 26, 89-105 (2008). https://doi.org/10.1016/j. biotechadv.2007.09.002

Bayrock, D.P. and Ingledew, W.M. Application of multistage continuous fermentation for production of fuel alcohol by very-high-gravity fermentation technology. Journal Industrial Microbiology Biotechnology, 27, 87-93 (2001). https://doi. org/10.1038/sj.jim.7000167

Blättel, V., Petri, A., Rabenstein, A., Kuever, J. and König, H. Differentiation of species of the genus Saccharomyces using biomolecular fingerprinting methods. Applied Microbiology Biotechnology, 97, 4597-4606 (2013). https://doi.org/10.1007/ s00253-013-4823-z
Blomberg, A. and Adler, L. Roles of glycerol and glycerol-3-phosphate dehydrogenase $\left(\mathrm{NAD}^{+}\right)$in acquired osmotolerance of Saccharomyces cerevisiae. Journal Bacteriology, 171, 1087-1092 (1989). https:// doi.org/10.1128/jb.171.2.1087-1092.1989

Blomberg, A. and Adler, L. Physiology of osmotolerance in fungi, Advanced Microbiology Physiology, 33, 145-212 (1992). https://doi. org/10.1016/S0065-2911(08)60217-9

Blomberg, A. Metabolic surprises in Saccharomyces cerevisiae during adaptation to saline conditions: questions, some answers and a model. FEMS Microbiology Letter, 182, 1-8 (2000). https://doi. org/10.1111/j.1574-6968.2000.tb08864.x

Birch, R.M. and Walker, G.M. Influence of magnesium ions on heat shock and ethanol stress responses of Saccharomyces cerevisiae. Enzyme Microbiology Technology, 26, 678-687 (2000). https://doi. org/10.1016/S0141-0229(00)00159-9

Boudjema, K., Fazouane-naimi, F., Hellal, A. Isolation, identification of yeast strains producing bioethanol and improvement of bioethanol production on cheese whey. Turkish Journal Biochemistry, 41, 157-166 (2016). https://doi.org/10.1515/tjb-2016-0026

Brooks, A.A. Ethanol production potential of local yeast strains isolated from ripe banana peels. Afr. Journal Biotechnology, 7, 3749-3752 (2008).

Cardona, C.A. and Sánchez, O.J. Fuel ethanol production: Process design trends and integration opportunities. Bioresource Technology, 98, 2415-2457 (2007). https://doi.org/10.1016/j. biortech.2007.01.002

Carneiro, M.L.N.M., Pradelle, F., Braga S.L., Gomes, S.M.P., Martins, A.R.F.A., Turkovics, F. and al. Potential of biofuels from algae: Comparison with fossil fuels, ethanol and biodiesel in Europe and Brazil through life cycle assessment (LCA). Renewable Sustainable Energy Reviews, 73, 632-653 (2017). https://doi.org/10.1016/j. rser.2017.01.152

Chandrasena, G., Keerthipala, A.P. and Walker, G.M. Isolation and Characterisation of Sri Lankan Yeast Germplasm and Its Evaluation for Alcohol Production. Journal of the Institute of brewing, 112, 302-307 (2006). https://doi. org/10.1002/j.2050-0416.2006.tb00735.x

Chen, Y. Development and application of co-culture for ethanol production by co-fermentation of glucose and xylose: a systematic review. Journal Industrial Microbiology Biotechnology, 38, 81-597 (2011). https://doi.org/10.1007/s10295-010-0894-3

Chniti, S., Djelal, H., Hassouna, M. and Amrane, A. Residue of dates from the food industry as a new cheap feedstock for ethanol production. Biomass Bioenergy, 69, 66-70 (2014). https://doi. org/10.1016/j.biombioe.2014.07.011 
da Silva, G.P., de Araújo, E.F., Silva, D.O. and Guimarães, W.V. Ethanolic fermentation of sucrose, sugarcane juice and molasses by Escherichia coli strain KO11 and Klebsiella oxytoca strain P2. Brazilian Journal Microbiology, 36, 395-404 (2005). https://doi.org/10.1590/S151783822005000400017

Dash, P.K., Jyoti, M., Patnaik, S.C., Swain, M.R. and Thatoi, H.N. Characterization, identification and comparative evaluation of bioethanol tolerance and production capacity of isolated yeast strains from fermented date palm sap (Toddy). Malaysian Journal Microbiology, 11, 223-230 (2015).

Demirbas, A. Biofuels securing the planet's future energy needs. Energy Conversion and Management, 50, 2239-2249 (2009). https://doi.org/10.1016/j. enconman.2009.05.010

Djelal, H., Chniti, S., Jemni, M., Weill, A., Sayed, W. and Amrane, A. Identification of strain isolated from dates (Phoenix dactylifera L.) for enhancing very high gravity ethanol production. Environmental Science Pollution Research, 24, 9886-9894 (2017). https://doi.org/10.1007/s11356-016-8018-x

Djelal, H., Larher, F., Martin, G. and Amrane, A. Continuous culture for the bioproduction of glycerol and ethanol by Hansenula anomala growing under salt stress conditions. Annals Microbiology, 62, 149-54 (2012). https://doi.org/10.1007/s13213011-0225-6

Djelal, H., Larher, F., Martin, G. and Amrane, A. Effect of the dissolved oxygen on the bioproduction of glycerol and ethanol by Hansenula anomala growing under salt stress conditions. Journal of Biotechnology, 125, 95-103 (2006). https://doi. org/10.1016/j.jbiotec.2006.02.005

Djelal, H., Larher, F, Martin, G and Amrane, A. Effect of medium osmolarity on the bioproduction of glycerol and ethanol by Hansenula anomala growing on glucose ans ammonium. Applied Microbiology Biotechnology, 69, 341-349 (2005). https://doi.org/10.1007/s00253-005-1987-1

Galafassi, S., Toscano, M. Vigentini, I., Piškur, J. and Compagno, C. Osmotic stress response in the wine yeast Dekkera bruxellensis. Food of Microbiology, 36, 316-319 (2013). https://doi.org/10.1016/j. fm.2013.06.011

Girard, V., Mailler, S., Welker, M., Arsac, M., Cellière, B., Cotte-Pattat, P.J. et al. Identification of mycobacterium spp. and nocardiaspp. from solid and liquid cultures by matrix-assisted laser desorption ionization-time of flight mass spectrometry (MALDI-TOF MS). Diagnostic Microbiology Infectious Disease, 86, 277-283 (2016). https://doi. org/10.1016/j.diagmicrobio.2016.07.027

Gruenwald, M., Rabenstein, A., Remesch, M. andKuever, J. MALDI-TOF mass spectrometry fingerprinting: A diagnostic tool to differentiate dematiaceous fungi Stachybotrys chartarum and Stachybotrys chlorohalonata. Journal Microbiology Methods, 115, 83-88 (2015). https:// doi.org/10.1016/j.mimet.2015.05.025

Gunasekaran, P. andRaj, K.C. Ethanol fermentation technology-Zymomonas mobilis. Current Science, 77, 56-68 (1999).

Hamouda, H.I., Nassar, H.N., Madian, H.R., ElSayed, M.H., El-Ghamry, A.A. andEl-Gendy, N.S. Isolation of fermentative microbial isolates from sugar cane and beet molasses and evaluation for enhanced production of bioethanol. Energy Sources Part Recovery Utilization and Environmental Effects, 38, 2170-2180 (2016). https://doi.org/10.1 080/15567036.2015.1030050

Harish, K.R.Y., Srijana, M., Madhusudhan, R.D. andGopal, R. Coculture fermentation of banana agro-waste to ethanol by cellulolytic thermophilic Clostridium thermocellum CT2. African Journal of Biotechnology, 9, 1926-1934 (2010). https://doi. org/10.5897/AJB09.1217

Holzinger, A., Herburger, K., Kaplan, F. and Lewis, L.A. Desiccation tolerance in the chlorophyte green alga Ulva compressa: does cell wall architecture contribute to ecological success? Planta, 42, 477492 (2015). https://doi.org/10.1007/s00425-0152292-6

Izmirlioglu, G. and Demirci A. Improved simultaneous saccharification and fermentation of bioethanol from industrial potato waste with co-culture of Aspergillus niger and Saccharomyces cerevisiae by medium optimization. Fuel, 185, 684-691 (2016). https://doi.org/10.1016/j.fuel.2016.08.035

Jadhav, S., Gulati, V., Fox, E.M., Karpe, A., Beale, D.J., Sevior, D. et al. Rapid identification and source-tracking of Listeria monocytogenes using MALDI-TOF mass spectrometry. International Journal Food Microbiology, 202, 1-9 (2015). https://doi.org/10.1016/j.ijfoodmicro.2015.01.023

Karagoz, P. and Ozkan, M. Ethanol production from wheat straw by Saccharomyces cerevisiae and Scheffersomyces stipitis co-culture in batch and continuous system. Bioresource Technology, 158, 286-293 (2014). https://doi.org/10.1016/j. biortech.2014.02.022

Klyani, D., Lee, K.M., Kim, T.S., Li, J., Dhiman, S.S., Kang, Y.C. and Lee, J.K. Microbial consortia for saccharification of woody biomass and ethanol fermentation. Fuel, 107, 815-822 (2013). https:// doi.org/10.1016/j.fuel.2013.01.037

Knauf, M. and Kraus, K. Specific yeasts developed for modern ethanol production. Sugar Industrial, 131, 753-758 (2006).

Kasavi, C., Finore, I., Lama, L., Nicolaus, B., Oliver, S.G., Oner, E.T. et al. Evaluation of industrial 
Saccharomyces cerevisiae strains for ethanol production from biomass, Biomass Bioenergy. 45, 230-238 (2012). https://doi.org/10.1016/j. biombioe.2012.06.013

Kudirkiene, E., Welker, M., Knudsen, N.R. and Bojesen, A.M. Rapid and accurate identification of Streptococcus equi subspecies by MALDI-TOF MS. Systeme Applied Microbiology, 38, 315-322 (2015). https://doi.org/10.1016/j.syapm.2015.02.010

Kurtzman, C., Fell, J.W. and Boekhout, T., The yeasts: a taxonomic study. Elsevier, (2011).

Lee, Y.J., Choi, Y.R., Lee, S.Y., Park, J.T., Shim, J.H., Park, K.H. et al.. Screening wild yeast strains for alcohol fermentation from various fruits. Mycobiology. 39, 33-39 (2011). https://doi. org/10.4489/MYCO.2011.39.1.033

Limtong, S., Sringiew, C. and Yongmanitchai, W. Production of fuel ethanol at high temperature from sugar cane juice by a newly isolated Kluyveromyces marxianus. Bioresource Technology, 98, 3367-3374 (2007). https://doi.org/10.1016/j. biortech.2006.10.044

Lv, X.C., Jia, R.B., Li, Y., Chen, F., Chen, Z.C., Liu, B. et al. Characterization of the dominant bacterial communities of traditional fermentation starters for Hong Qu glutinous rice wine by means of MALDI-TOF mass spectrometry fingerprinting, 16S rRNA gene sequencing and species-specific PCRs. Food Control, 67, 292-302 (2016). https:// doi.org/10.1016/j.foodcont.2016.03.005

Mehdikhani, P., Bari, M.R. and Hovsepyan, H. Screening of Saccharomyces cerevisiae for high tolerance of ethanol concentration and temperature. African Journal of Microbiology Research, 5, 26542660 (2011). https://doi.org/10.5897/AJMR11.251

Mobini-Dehkordi, M., Nahvi, I., Ghaedi, K. and Tavassoli, M. Isolation of high ethanol resistant strains of Saccharomyces cerevisiae. Research Pharmaceutical Sciences, 1, 85-91 (2007).

Moothoo-Padayachie, A., Kandappa, H.R., Krishna, S.B.N., Maier, T. and Govender, P. Biotyping Saccharomyces cerevisiae strains using matrixassisted laser desorption/ionization time-of-flight mass spectrometry (MALDI-TOF MS). European Food Research Technology, 236, 351-364 (2013). https://doi.org/10.1007/s00217-012-1898-1

Nasir, A., Rahman, S.S., Hossain, M.M. and Choudhury, N. Isolation of Saccharomyces cerevisiae from pineapple and orange and study of metal's effectiveness on ethanol production. European Journal Microbiology Immunology, 7, 76-91 (2017). https://doi.org/10.1556/1886.2016.00035

Negi, B., Sharma, P., Kashyap, S., Seth, S. and Dey, G. Screening of yeast strains for vinification of fruits from cold desert regions of North West India. International Food Research Journal, 20, 975-979 (2013).
Ntaikou, I., Menis, N., Alexandropoulou, M. and Antonopoulou, G. Valorization of kitchen biowaste for ethanol production via simultaneous saccharification and fermentation using co-culture of the yeasts Saccharomyces cerevisiae and Pichia stipitis. Bioressource technology, 263, 75-83 (2018). https://doi.org/10.1016/j.biortech.2018.04.109

Nwachukwu, I.N., Ibekwe, V.I., Nwabueze, R.N. and Anyanwu, B.N. Characterisation of palm wine yeast isolates for industrial utilisation. African Journal Biotechnology, 5, 1725-1728 (2006).

Osho, A. Ethanol and sugar tolerance of wine yeasts isolated from fermenting cashew apple juice. African Journal Biotechnology, 4, 660-662 (2005). https://doi.org/10.5897/AJB2005.000-3119

Patil, S.K. and Patil,A.B. Isolation and Characterization of Wine Yeast From Pineapple Fruits. Karnataka Journal Agriculture Science, 19, 558-561 (2010).

Patrascu, E., Rapeanu, G. and Hopulele, T. Current approaches to efficient biotechnological production of ethanol. Innovation Romanian Food Biotechnology, 4: 1-11 (2009).

Prescott, L.M., Harley, J.P., Klein, D., Willey, J.M., Sherwood, L.M., Woolverton, C.J. Microbiologie, $3^{\text {th }}$ Editions. De Boeck, (2010).

Ramos, C.L., Duarte, W.F., Freire, A.L., Dias, D.R., Eleutherio, E.C.A. and Schwan, R.F., Evaluation of stress tolerance and fermentative behavior of indigenous Saccharomyces cerevisiae. Brazilian Journal Microbiology, 44, 935-944 (2013). https:// doi.org/10.1590/S1517-83822013005000051

Rédou, V., Navarri, M., Meslet-Cladière, L., Barbier, G. and Burgaud, G. Marine Fungi from Deep Subseafloor Sediments: Species richness and Adaptation. Applied Environmental Microbiology, 81, 571-3583 (2015). https://doi.org/10.1128/ AEM.04064-14

Russell, I., Jones, R. and Stewart, G.G. Yeast-the primary industrial microorganism. Biological Research Industrial Yeasts. Editors Stewart GG, Klein RD, Hiebsch RR, CRC Press, Boca Raton, 1-20 (1987).

Sayed, W., Cabrol., A., Abdallah, R., Taha, S., Amrane, A. and Djelal, H. Enhancement of ethanol production from synthetic medium model of hydrolysate of macroalgae, Renewable Energy Journal, 124, 3-10 (2017). https://doi.org/10.1016/j. renene.2017.10.094

Shanghaghi-Moghaddam, R., Jafarizadeh-Malmiri, H., Mehdikhani, P., Jalalian, S. and Alijanjanzadeh, R. Screening of the five different wild, traditional and industrial Saccharomyces cerevisiae strains to overproduce bioethanol in the batch submerged fermentation. Zeitschrift für Naturforschung C, 73, (2017). https://doi.org/10.1515/znc-2017-0180 
Shanghaghi-Moghaddam, R., Jafarizadeh-Malmiri, H. and Mehdikhani, P. Optimization of submerged fermentation conditions to overproduce bioethanol using two industrial and traditional Saccharomyces cerevisiae strains. Green Process Synth Journal, 8, (2018). https://doi.org/10.1515/gps-2018-0044

Sharma, Y.C., Singh, B. and Upadhyay, S.N. Advancements in development and characterization of biodiesel: A review. Fuel, 87, 2355-2373 (2008). https://doi.org/10.1016/j.fuel.2008.01.014

Sheoran,A.,Yadav,B.S.,Nigam,P.andSingh,D.Continuous ethanol production from sugarcane molasses using a column reactor of immobilized Saccharomyces cerevisiae HAU-1. J. Basic Microbiology 38, 123-128 (1998). https://doi.org/10.1002/ (SICI) 1521-4028(199805)38:2\%3C123::AIDJOBM123\%3E3.0.CO;2-9

Singh, A. and Bishnoi, N.R. Enzymatic hydrolysis optimization of microwave alkali pretreated wheat straw and ethanol production by yeast. Bioresource Technology, 108, 94-101 (2012). https://doi. org/10.1016/j.biortech.2011.12.084

Tantipaibulvut, S., Pinisakul, A., Rattanachaisit, P., Klatin, K., Onsriprai, B. and Boonyaratsiri, K. Ethanol production from desizing wastewater using co-culture of Bacillus subtilis and saccharomyces cerevisiae; Energy Procedia, 79, 1001-1007 (2015). https://doi.org/10.1016/j.egypro.2015.11.600

Techaparin, A., Thanonkeo, P. and Klanrit, P. High-temperature ethanol production using thermotolerant yeast newly isolated from Greater Mekong Subregion. Brazilian Journal Microbiology, 48, 461-475 (2017). https://doi. org/10.1016/j.bjm.2017.01.006

Tikka, C., Osuru, H.P., Atluri, N., Raghavulu, P.C.V., Yellapu, N.K., Mannur, I.S. and al. 2013. Isolation and characterization of ethanol tolerant yeast strains. Bioinformation, 9, 421-425 (2013). https:// doi.org/10.6026/97320630009421

van Maris, A.J., Abbott, D.A., Bellissimi, E., van den Brink, J., Kuyper, M., Luttik, M.A.H. and al. Alcoholic fermentation of carbon sources in biomass hydrolysates by Saccharomyces cerevisiae: current status. Antonie Van Leeuwenhoek, 90, 91418 (2006). https://doi.org/10.1007/s10482-0069085-7

Vijaikishore, P. and Karanth, N.G. Glycerol production by fermentation. Applied Biochemistry Biotechnology, 9, 243-253 (1984). https://doi. org/10.1007/BF02798490

Walker, L.P. and Wilson, D.B. Enzymatic hydrolysis of cellulose: An overview. Bioresource Technology, 36, 3-14 (1991). https://doi.org/10.1016/09608524(91)90095-2

Watson, T.G. Effects of sodium chloride on steadystate growth and metabolism of Saccharomyces cerevisiae. Microbiology, 64, 91-99 (1970).

Wheals, A.E., Basso, L.C., Alves, D.M.G. and Amorim, V. Fuel ethanol after 25 years. Trends Biotechnology, 17, 482-487 (1999). https://doi. org/10.1016/S0167-7799(99)01384-0

Ylitervo, P., Franzén, C.J. and Taherzadeh M.J. Ethanol production at elevated temperatures using encapsulation of yeast. Journal Biotechnology, 156, 22-29 (2011). https://doi.org/10.1016/j. jbiotec.2011.07.018

Zabed, H., Sahu, J.N., Boyce, A.N. and Faruq, G. Fuel ethanol production from lignocellulosic biomass: An overview on feedstocks and technological approaches. Renewable Sustainable Energy Reviews, 66, 751-774 (2016). https://doi. org/10.1016/j.rser.2016.08.038 
